\title{
Serum Levels of Oncofetal Markers CA 125, CA 19-9, and $\alpha$-Fetoprotein in Children with Hereditary Tyrosinemia Type I
}

\author{
SARI PITKÄNEN, MATTI K. SALO, PENTTI KUUSELA, CHRISTER HOLMBERG, OLLI SIMELL. \\ AND MARKKU HEIKINHEIMO'
}

Children's Hospital [S.P., C.H., M.H.] and Department of Bacteriology and Immunology [P.K.]. University of Helsinki, 00290 Helsinki, and Departments of Pediatrics, Universities of Tampere, 33520 Tampere [M.S.J. and Turku, 20520 Turku /O.S.J. Finland

\begin{abstract}
Hereditary tyrosinemia type I (HTT-I) is an inherited metabolic disorder with severe liver disease and a high risk for hepatic malignancy. Patients with HTT-I are monitored with repeated analyses of serum amino acids, urine succinylacetone, and serum $\alpha$-fetoprotein (AFP). Oncofetal markers CA 125 and CA 19-9 are elevated in serum of patients with various gastrointestinal diseases and malignancy. To study the biology of oncofetal antigens in tyrosinemia and to assess the possible usefulness of these markers in HTT-I, we studied serum concentrations of CA $125(n=160)$ and CA $19-9(n=188)$, together with AFP $(n=337)$, in serial samples from 10 patients. At early stages of the disease, most children with an acute type of disease had a remarkably elevated serum $C A 125$ concentration (153-1560 IU/L) that normalized gradually after the institution of therapy. Serum CA 125 levels may thus reflect acute metabolic imbalance in fulminant HTT-I. The patients with a chronic type of disease showed CA 125 levels within the normal range at diagnosis that slowly increased as the liver condition worsened. These concentrations, however, never reached values seen in acute HTTI. Serum concentration CA 19-9 in HTT-I was mostly normal. Serum AFP levels fluctuated in all patients and positively correlated with tests for metabolic state and biliary function. A distinct increase in the serum AFP level was recorded in association with the detection of massive hepatocellular carcinoma and also preceded metabolic imbalance leading to porphyria crises. Fluctuations in serum AFP concentration, however, limit its usefulness in early detection of developing hepatic malignancies or porphyria crises in HTT-I. Serum CA 125 or CA 19-9 are also unlikely to offer diagnostic tools for detecting developing hepatocellular carcinoma in HTT-I. (Pediatr Res 35: 205208, 1994)
\end{abstract}

\section{Abbreviations}

AFP, $\alpha$-fetoprotein

HCC, hepatocellular carcinoma

HTT-I, hereditary tyrosinemia type I

\footnotetext{
Received May 3, 1993; accepted September 16, 1993.
}

Correspondence: Markku Heikinheimo. Washington University School of Medicine, St. Louis Children's Hospital. Division of Pediatric Hematology-Oncology, One Children's Place, St. Louis. MO 63110.

Supported by grants from Emil Aaltonen Foundation and the Foundation for Pediatric Research. Finland.

'Present address: Washington University School of Medicine, St. Louis Children's Hospital, Division of Pediatric Hematology-Oncology, One Children's Place. St. Louis, MO 63110
HTT-I is an inborn error of tyrosine metabolism caused by a deficiency of fumarylacetoacetase, an enzyme most abundantly present in the liver and kidney (1). HTT-I manifests with either acute hepatic failure during the neonatal period or with liver cirrhosis, rickets, and renal tubulopathy in infancy. The treatment with a low-tyrosine, low-phenylalanine diet usually ameliorates the clinical symptoms and improves liver function. Biochemical monitoring of the patients is performed by regular analyses of plasma amino acids and AFP concentration $(2,3)$. However, even during the most strict diet, the accumulation of toxic tyrosine metabolites persists, leading to an inevitable progression of the liver disease with a high risk of malignancy. HCC develops in at least $37 \%$ of patients surviving beyond the age of $2 y$ (4). Because of the high risk of cancer and the poor prognosis, an early liver transplantation is today the treatment of choice for these children. However, the recent finding of restraining the accumulation of toxic metabolites by 4-hydroxyphenylpyruvate dioxygenase inhibition may offer an alternative therapy (5).

AFP, an oncodevelopmental glycoprotein, is produced primarily by the fetal yolk sac and liver (6). In addition, increased AFP production is associated with hepatic regeneration and malignancy (7). In tyrosinemia, the liver always produces elevated levels of serum AFP (8). No exact analyses concerning the effect of the dietary balance and the liver function on the serum AFP concentration in HTT-I are available. Malignant transformation in patients with tyrosinemia induces a further rise in the AFP concentration, but early recognition of the developing malignancy may be delayed because of constantly high and fluctuating AFP levels.

We have studied the expression of two tumor markers, CA 125 and CA 19-9, in patients with HTT-I. Both markers are detected by $\mathrm{MAb}$ originally raised against cystadenocarcinoma and colorectal cell line, respectively $(9,10)$. They are known to be expressed in adult patients with various gastrointestinal malignancies $(11,12)$, and elevated serum levels have been reported in patients with $\mathrm{HCC}(13,14)$. On the basis of these data and realizing the possible pitfalls of serum AFP measurements, we started to use measurements of serum CA 125 and CA 19-9 to detect tumors in the HTT-I livers at an early stage of the disease and to gain information on the biology of CA 125 and CA 19-9 in this disease. Moreover, the relationship of serum AFP concentrations to the new tumor markers and to the clinical and metabolic state in children with tyrosinemia was studied in detail.

\section{PATIENTS AND METHODS}

Patients. Ten patients, three girls and seven boys with HTT-I, were followed up for 0.2 to 2.6 y after diagnosis at the Children's Hospital, University of Helsinki, and the University Hospital of 
Tampere and Turku in Finland from 1986 to 1991. Mean age at the diagnosis was $0.8 \mathrm{y}$ (range, 0.1 to $3.0 \mathrm{y}$ ).

The diagnosis was based on a characteristic clinical picture, a high plasma tyrosine and methionine concentration, and an increased urinary excretion of succinylacetone (Table 1). In six of the patients the diagnosis was confirmed by fibroblast fumarylacetoacetase determination. All patients had coagulopathy, low serum albumin levels, high serum AFP levels, and high urinary excretion of $\delta$-aminolevulinate together with extremely low erythrocyte $\delta$-aminolevulinate dehydratase activity. The patients were treated with a low-tyrosine, low-phenylalanine diet supplemented with other essential amino acids. Four of them also received $N$-acetylcysteine.

During this study, six patients underwent orthotopic liver transplantation at a mean age of $1.6 \mathrm{y}$ (range, 0.4 to $2.7 \mathrm{y}$ ), and two patients are on the transplant list. All children who had transplants are alive and without any signs of malignancy after a follow-up of 0.1 to $2.3 \mathrm{y}$.

Acute type of HTT-I. Six patients (Table 1, patients 1-6) had an acute type of HTT-I (onset of symptoms at $<6$ mos of age). Their mean age at diagnosis was $0.4 \mathrm{y}$ (range, $0.2-0.5 \mathrm{y}$ ). At this point, all six children had tumor-like liver nodules visualized by ultrasonography or computed tomography. These children were followed up for 0.2 to $1.4 \mathrm{y}$ from diagnosis. One of them (patient 3 ) had areas of malignant cell clusters in her liver at transplantation performed $1 \mathrm{y}$ after the detection of the disease.

Chronic type of HTT-I. Four patients (Table 1, patients 7-10) had a chronic type of HTT-I (onset of symptoms at $>6$ mo of age). Mean age at diagnosis of these children was $1.3 \mathrm{y}$ (range. 0.1-3.0 y). Early diagnosis of patient 10 (at age 0.1 y) was based on neonatal screening because of positive family history. One of these four patients (patient 9 ) had radiologically detectable nodules in the liver at the time of diagnosis. Patients with chronic HTT-I were followed up for 0.7 to $2.6 \mathrm{y}$ from diagnosis. Two of them (patients 8 and 10) had several porphyria crises (at the ages of 3.2-3.7 and 1.5-2 y, respectively), which were treated by i.v. heme arginate (Leiras Pharm, Turku, Finland). Two patients (patients 7 and 8 ) died before liver transplantation was available: one died at $2.4 \mathrm{y}$ of $\mathrm{HCC}$, and the other at $3.7 \mathrm{y}$ of septic infection.

Laboratory investigations. Altogether. 298 serum samples (mean number of samples per patient. 30; range. 7 to 90) were collected for AFP measurements. They were subsequently used for additional analyses of the newer markers.
Serum levels of CA 125. CA 19-9, and AFP were measured using commercially available RIA (Abbott Laboratories, North Chicago, IL), with sensitivity limits of $5.3 \mathrm{IU} / \mathrm{L}$. 5.6 IU/L, and $1 \mu \mathrm{g} / \mathrm{L}$, respectively. The reference values of these markers for children more than $1 \mathrm{y}$ of age have been reported using the same laboratory conditions recommended by the manufacturer $(15$. 16). The normal 90th percentile in this age group for CA 125 is $22 \mathrm{IU} / \mathrm{L}$, and for CA $19-9$ it is $56 \mathrm{IU} / \mathrm{L}$. We also studied 39 children who were 0.1 to 1.0 y old for serum CA 125 and CA $19-9$ reference values at this age group. Samples were collected in association with elective neonatal surgery in otherwise healthy children. The normal upper 90th percentile for CA 125 was 40 $\mathrm{IU} / \mathrm{L}$ at age $0.1-0.5 \mathrm{y}$ and $22 \mathrm{IU} / \mathrm{L}$ at age $0.5-1.0 \mathrm{y}$, and the corresponding values for CA $19-9$ were $25 \mathrm{IU} / \mathrm{L}$ and $45 \mathrm{IU} / \mathrm{L}$.

The metabolic control of the disease was monitored by measurements of plasma amino acid concentration, urinary excretion of succinylacetone, and erythrocyte $\delta$-aminolevulinate dehydratase activity. The routine investigations during the follow-up included measuring the values of serum liver aminotransferases, $\gamma$-glutamyl transpeptidase, alkaline phosphatase, bilirubin, albumin, protein, C-reactive protein and creatinine concentration, prothrombin time, urinary excretion of $\delta$-aminolevulinate, and liver ultrasonography. Because we minimized the blood drawn for sampling. it was not always possible to measure all these parameters at the same time point. Values from eight patients were used for comparisons because of insufficient simultaneous laboratory data from the two earliest cases.

Statistical analyses. The Spearman rank correlation was used to compare serum tumor marker levels with other laboratory data.

\section{RESULTS}

Serum CA 125 Concentration. Serum CA 125 was analyzed in 160 serum samples obtained from patients with HTT-I, and the levels ranged from $<5.3$ to $1560 \mathrm{IU} / \mathrm{L}$. Forty-two percent of the samples showed a serum CA 125 concentration above the normal 90 th percentile.

1. Acute type of HTT-I. Four of the six patients with acute disease (patients 3-6) had remarkably elevated serum CA 125 levels at diagnosis $(153,1560,500$, and 464 IU/L, respectively). which declined to normal within 4 mo (Fig. 1.1). Two of the six patients (patients 1 and 2) had normal values at diagnosis, which

Table 1. Age, diagnostic laboratory parameters, and other information in children with tyrosinemia

\begin{tabular}{|c|c|c|c|c|c|c|}
\hline Patient no. & $\begin{array}{l}\text { Age at di- } \\
\text { agnosis }(\mathrm{y})\end{array}$ & $\begin{array}{l}\mathrm{P}-\mathrm{tyr} / \mathrm{met} \\
(\mu \mathrm{mol} / \mathrm{L})^{*}\end{array}$ & $\begin{array}{c}\text { U-SA } \\
(\mathrm{mmol} / \\
\text { mol creat }) \dagger\end{array}$ & $\begin{array}{l}\mathrm{S}-\mathrm{AFP}(\mu \mathrm{g} / \mathrm{L} / \\
\mathrm{MOM}) \ddagger\end{array}$ & $\begin{array}{c}\text { Follow-up } \\
\text { time }(y)\end{array}$ & Other information \\
\hline \multicolumn{7}{|l|}{ Acute HTT-I } \\
\hline 1 & 0.2 & $833 / 1050$ & 110 & $87145 / 423$ & 0.2 & Tx at age $0.4 \S$ \\
\hline 2 & 0.5 & $600 / 800$ & - & $187500 / 15625$ & 0.2 & Tx at age 1.0 \\
\hline 3 & 0.4 & $206 /-$ & - & $107718 / 3591$ & 1.4 & $\begin{array}{l}\text { Tx at age } 1.8 \text {, areas of malignant cell clusters in } \\
\text { the liver at } T x\end{array}$ \\
\hline 4 & 0.4 & $185 / 438$ & 197 & $76200 / 990$ & 0.4 & On the transplant list \\
\hline 5 & 0.5 & $659 / 749$ & 778 & $127636 / 42550$ & 0.6 & Tx at age 1.1 \\
\hline 6 & 0.2 & $383 / 206$ & 580 & $142600 / 692$ & 0.7 & On the transplant list \\
\hline \multicolumn{7}{|c|}{ Chronic HTT-I } \\
\hline 7 & 1.4 & $404 / 347$ & - & $75000 / 10714$ & 0.9 & Died of HCC at age 2.4 \\
\hline 8 & 3.0 & $447 / 10$ & - & $1500 / 214$ & 0.7 & $\begin{array}{l}\text { Porphyria crises at age } 3.2-3.7 \text {; died from } \\
\text { sepsis at age } 3.7\end{array}$ \\
\hline 9 & 0.7 & $278 / 48$ & 87 & $212700 / 17725$ & 1.6 & Tx at age 2.3 \\
\hline 10 & 0.1 & $370 / 33$ & 376 & $199000 / 6$ & 2.6 & Porphyria crises at age $1.5-2 ; \mathrm{Tx}$ at age 2.7 \\
\hline
\end{tabular}

* Upper normal limit for plasma tyrosine (P-tyr): age $<0.3 \mathrm{y},<97 \mu \mathrm{mol} / \mathrm{L}$, and age $\geq 0.3 \mathrm{y},<121 \mu \mathrm{mol} / \mathrm{L}$. Upper limit for plasma methionine (P-met): age $<0.3 \mathrm{y},<24 \mu \mathrm{mol} / \mathrm{L}$, and age $\geq 0.3 \mathrm{y},<30 \mu \mathrm{mol} / \mathrm{L}$.

+ Upper normal limit for urine succinylacetone (U-SA) $<10 \mathrm{mmol} / \mathrm{mol}$ creatinine (creat).

‡ S-AFP, Serum AFP: MOM, multiples of age-related median (shown for AFP because of remarkable change in reference values with age).

$\S \mathrm{Tx}$, liver transplantation. 

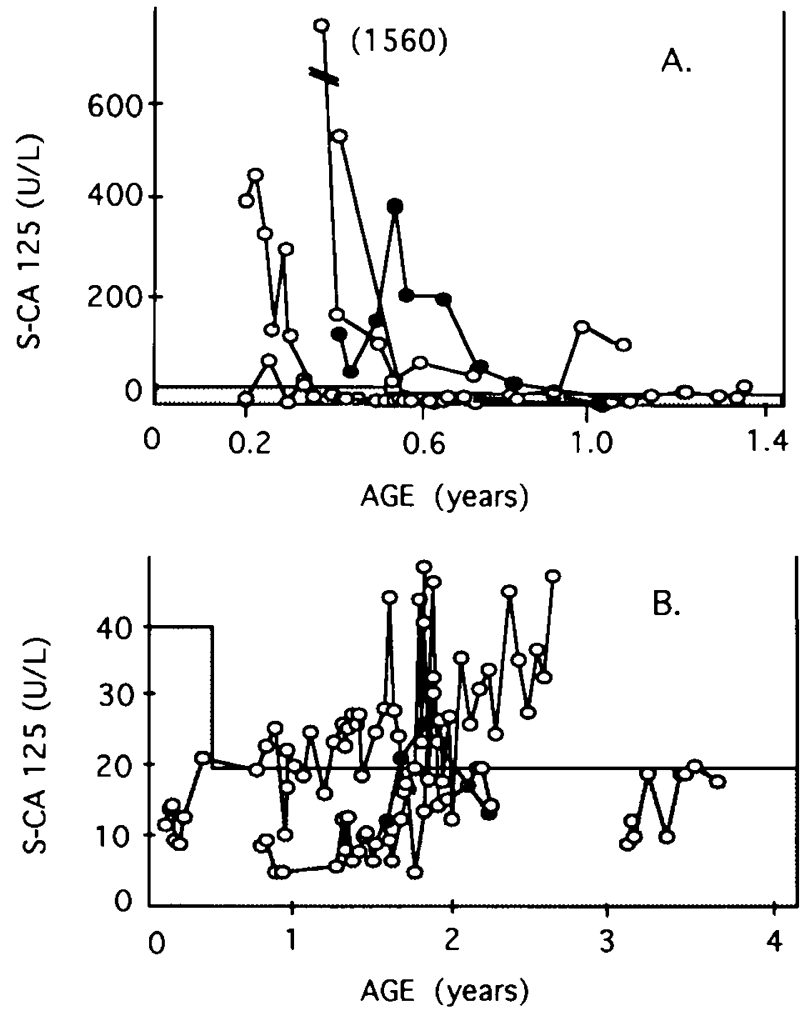

Fig. 1. Serum CA 125 concentrations during the follow-up in patients with hereditary tyrosinemia. Two patterns were seen: the patients with acute disease showing decreasing levels during the time course $(A)$ and the patients with chronic disease showing increasing levels with advancing disease $(B)$. The shaded area shows the normal range for CA 125 in children. The two patients with a later $\mathrm{HCC}$ are indicated with dark dots. Note the different time and CA 125 scales in $A$ and $B$.

elevated rapidly above the reference range during the first 4 mo before early liver transplantation.

2. Chronic type of HTT-I. Patients 9 and 10 with chronic type of disease had normal values at diagnosis, which slowly increased during the follow-up (Fig. $1 B$ ). The highest serum CA 125 peaks in patient 10 coincided with the episodes of porphyria crises and neurologic symptoms (Fig. 2). Patients 7 and 8 , with late manifestation of the disease, constantly showed normal serum CA 125 values.

3. Hepatic malignancy. Patient 7 died of $\mathrm{HCC}$ without any alteration in her serum CA 125 level, whereas her serum AFP concentration increased with advancing disease. Also, serum CA 125 did not elevate in the one patient (patient 3) with areas of malignant cell clusters in her liver at transplantation before this operation.

No significant correlation between serum CA 125 values and laboratory parameters for the metabolic control of HTT-I, liver function, or other tests was noted.

Serum CA 19-9 Concentration. Serum CA 19-9 values varied from $<5.6$ to $85 \mathrm{IU} / \mathrm{L}$ and were within the normal range in 182 $(97 \%)$ of the 188 samples. The type of tyrosinemia or the occurrence of malignancy did not affect the serum CA 19-9 levels. Slightly elevated concentrations $(85 \mathrm{IU} / \mathrm{L})$ were seen in only one patient at diagnosis (patient 1). He was the youngest patient and had the most severe and acute type of HTT-I, manifesting at the age of $6 \mathrm{wk}$ with acute liver failure. His CA 19-9 level normalized after institution of dietary treatment supplemented with intravenous glutathione.

Serum AFP Concentration. Serum AFP was measured in a total of 337 samples. In all patients, serum AFP levels were elevated at diagnosis and ranged from 1500 to $213000 \mu \mathrm{g} / \mathrm{L}$. corresponding to 6.0 to 17725 multiples of the age-related
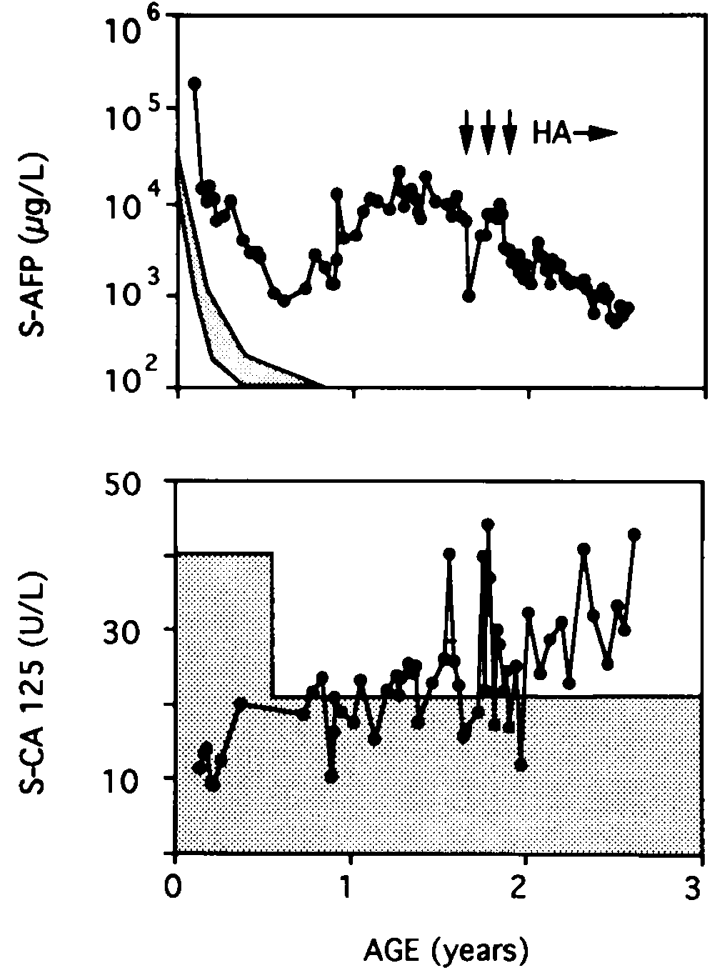

Fig. 2. Serum AFP (upper panel) and CA 125 (lower panel) levels in patient 4 with a chronic type of hereditary tyrosinemia. Note the continuous decrease in serum AFP and increase in serum CA 125 values during regular prophylactic treatment with heme arginate (H.4). Episodes of porphyria are indicated by arrows. The shaded areas show the reference range for serum AFP and CA 125 levels.

median (Table 1). The AFP levels decreased in all patients after the institution of therapy and with advancing age but still remained abnormally high.

1. Acute type of HTT-I. All patients with acute tyrosinemia had a fluctuating serum AFP level without any clear correlation with metabolic control or clinical picture. The lowest and highest AFP values in these six patients ranged from 14000 to 28000 $\mu \mathrm{g} / \mathrm{L}$ (mean, $21000 \mu \mathrm{g} / \mathrm{L}$ ) and from 48000 to $132000 \mu \mathrm{g} / \mathrm{L}$ (mean, $82000 \mu \mathrm{g} / \mathrm{L}$ ), respectively, corresponding to a 1.9- to 7.6fold variation in the serum AFP level.

2. Chronic type of HTT-I. The patients with chronic disease had rather stabile serum AFP levels during the long follow-up period. Two clear exceptions with more than 10 -fold increases in serum AFP levels were noted: in patient 10 before porphyria crises (from 1000 to $21000 \mu \mathrm{g} / \mathrm{L}$. Fig. 2) and in patient 7 before diagnosis of HCC (from 25000 to $250000 \mu \mathrm{g} / \mathrm{L}$ ).

3. Hepatic malignancy. One of the patients with the acute type of HTT-I (patient 3) had areas of malignant cell clusters in her liver at transplantation, but she had only 2 -fold increases in the serum AFP level (from 27000 to $55000 \mu \mathrm{g} / \mathrm{L}$ ) during the preceding 2 mo. The other patient with the chronic type of HTTI (patient 7) had a 10-fold increase in the serum AFP level (from 25000 to $250000 \mu \mathrm{g} / \mathrm{L}$ ) before she died of HCC.

A positive correlation between serum AFP level and some markers for the metabolic control (serum methionine, $n=151$. $p=0.0002$; tyrosine, $n=157, p=0.0002$ ) and parameters for liver function (serum alkaline phosphatase, $n=95, p=0.0001$ : total bilirubin, $n=61, p=0.0001$; conjugated bilirubin, $n=33$. $p=0.002 ;$ and $\gamma$-glutamyl transpeptidase, $n=77, p=0.0001$ ) was observed.

\section{DISCUSSION}

HTT-I is seen at diagnosis with either acute, rapidly evolving hepatic failure or a more chronic hepatopathy with sequential 
progression from micronodular to macronodular cirrhosis and regenerative foci susceptible to malignant transformation (17). The liver damage is thought to be caused by toxic tyrosine metabolites, maleylacetoacetate and succinylacetoacetate, which accumulate regardless of an adequate dietary therapy (3).

The tumor markers CA 125 and CA 19-9 are elevated in adults with gastrointestinal malignancy and are thus candidate markers for malignant transformation in the pathologic liver tissue in hereditary tyrosinemia. The possible oncofetal nature of CA 125 and $C A$ 19-9 is suggested by their strong expression in fetal tissues $(9,11,12)$. Our results on CA 125 support this view: the enhanced production of CA 125 in HTT-I, analogous to AFP. may be a consequence of a fetal type of gene expression in tyrosinemia. In contrast to CA 125 and AFP, the pattern of CA 19-9 expression was not shifted to such a fetal direction.

Most of the patients with acute HTT-I had remarkably elevated serum CA 125 levels during the first months of the disease, which gradually normalized after the institution of dietary therapy. These children also had radiologically detectable liver nodules at diagnosis. High initial serum CA 125 concentration may thus indicate a fulminant onset of the disease and reflect the metabolic state within the liver. This view is supported by the association of elevated serum CA 125 level and episodes of porphyria. However, no significant correlation between serum CA 125 level and laboratory parameters for metabolic state was noted. The patients with a chronic type of disease and long follow-up periods showed slowly increasing serum CA 125 levels. The increasing serum CA 125 level in these patients can reflect the progression of liver damage and development of macronodular cirrhosis.

In contrast to serum CA 125 , the concentrations of CA 19-9 were practically always within reference values. This was also the case in the two patients with HCC. Serum CA $19-9$ measurements are thus not valuable in the follow-up of patients with HTT-I.

Serum AFP measurements have been used in the early diagnosis of hereditary tyrosinemia $(8,18)$ and as an indicator of hepatic malignancy. The constantly elevated levels of AFP, however, hamper its use as a marker for the development of malignancy in hereditary tyrosinemia. The AFP levels at diagnosis varied over a wide range from patient to patient, possibly indicating various degrees of liver damage in these children. During the follow-up, the concentrations remained abnormally high, and minor fluctuations occurred in all patients. The noted clear correlations between serum AFP level and laboratory parameters of the liver function suggest that the fluctuations in serum AFP levels may reflect the pathologic condition of the liver in HTTI. In two children, a marked elevation in serum AFP levels during the therapy was noted: in one of them, hepatic malignancy was subsequently detected, and in the other one the increase in serum AFP level preceded episodes of porphyria. Thus, even a clear increase in the serum AFP level does not always mean the development of malignancy in the liver. Furthermore, one of the two patients with malignancy (histologically proven at transplan- tation, but clinically not evident) did not have a clear elevation in the serum AFP level.

We conclude that fluctuations in serum AFP concentration limit its usefulness in early detection of developing hepatic malignancies or porphyria crises in children with tyrosinemia. Serum CA 125 levels were mostly highly elevated at the early phase of acute tyrosinemia. Measurements of serum CA 125 or CA 19-9 levels do not, however, seem to offer diagnostic tools for determining whether HCC is developing in these patients because the levels were normal in the two patients in whom a histologically proven overt hepatic malignancy developed.

\section{REFERENCES}

1. Lindblad B, Lindstedt S, Steen G 1977 On the enzymatic defect in hereditary tyrosinemia. Proc Natl Acad Sci USA 74:4641-4645

2. Kvittingen EA 1986 Hereditary tyrosinemia type I: an overview. Scand J Clin Lab Invest 184:27-34

3. Goldsmith LA, Laberge C 1989 Tyrosinemia I. In: Scriver CR. Beaudet AL. Sly WS, Valle D (eds) The Metabolic Basis of Inherited Disease. McGrawHill Co. New York, pp 556-562

4. Weinberg AG, Mize CE. Worten HG 1976 The occurrence of hepatoma in the chronic form of hereditary tyrosinemia. J Pediatr 88:434-438

5. Lindstedt S, Holme E, Lock EA, Hjalmarson O, Strandvik B 1992 Treatment of hereditary tyrosinemia type I by inhibition of 4-hydroxyphenylpyruvate dioxygenase. Lancet 340:813-817

6. Gitlin D, Boesman M 1966 Serum alfa-fetoprotein, albumin and gammaglobulin in the human conceptus. J Clin Invest 45:1826-1837

7. Abelev GI, Assecritova IV, Kraevsky NA. Perova SD. Perevodchikova NI 197 Embryonal serum alpha-globulin in cancer patients: diagnostic value. Int $\mathrm{J}$ Cancer 2:551-558

8. Grenier A, Belanger L. Laberge C 1976 Alpha-fetoprotein measurement in blood spotted on paper: discriminating test for hereditary tyrosinemia in neonatal mass screening. Clin Chem 22:1001-1004

9. Bast RC, Klug TL. St John E, Jenison E. Niloff JM, Lazarus H, Berkowitz RS Leavitt T. Griffiths CT. Parker L, Zurawski VR, Knapp RC 1983 A radioimmunoassay using monoclonal antibody to monitor the course of epithelial ovarian cancer. N Engl J Med 309:883-887

10. Koprowski H. Steplewski Z, Mitchell K. Meenhard H. Herlyn D. Fuhrer P 1976 Colorectal carcinoma antigens detected by hybridoma antibodies. Somat Cell Genet 5:957-971

11. Raux H, Labbe F. Fondaneche C-M. Koprowski H. Burtin P 1983 A study of gastrointestinal cancer-associated antigen (GICA) in human fetal organs. Int J Cancer 32:315-319

12. Dietel M. Arps H, Klapdor R, Muller-Hagen S, Sieck M. Hoffman L 1986 Antigen detection by the monoclonal antibodies $\mathrm{Ca} 19.9$ and $\mathrm{Ca} 125$ in normal and tumor tissue and patients sera. $\mathrm{J}$ Cancer Res Clin Oncol 111:257265

13. Jalanko H, Kuusela $P$, Roberts $P$, Sipponen $P$. Haglund $C$ Mäkelä $O 1984$ Comparison of new tumor marker. CA 19-9 TM, with alpha-fetoprotein and carcinoembryonic antigen in patients with upper gastrointestinal diseases. J Clin Pathol 37:218-222

14. Haglund C. Kuusela P, Roberts PJ, Jalanko H 1991 Tumor marker CA 125 in patients with digestive tract malignancies. Scand J Clin Lab Invest 51:265270

15. Heikinheimo M. Rajantie J. Kuusela P. Kallio MJT. Siimes MA 1990 Oncofetal markers CA 19-9. CA 125 and SP1 in healthy children and in children with leukemia and solid tumors. Br J Cancer 62:865-867

16. Lahdenne P. Kuusela P, Siimes MA, Rönnholm KAR, Salmenperä L, Heikinheimo M 1991 Biphasic reduction and concanavalin A binding properties of serum alpha-fetoprotein in preterm and term infants. J Pediatr 1 18:272276

17. Dehner LP, Snover DC. Sharp HL, Ascher N, Nakhleh R, Day DL 1989 Hereditary tyrosinemia type I (chronic form): pathologic findings in the liver. Hum Pathol 20:149-158

18. Grenier A, Laberge C 1974 A modified automated fluorometric method for tyrosine determination in blood spotted on paper: a mass screening procedure for tyrosinemia. Clin Chim Acta 57:71-75 